\title{
PHYSICAL AND MECHANICAL PROPERTIES OF NANOREINFORCED PARTICLEBOARD COMPOSITES
}

\author{
Zeki Candan ${ }^{1, \wedge}$, Turgay Akbulut ${ }^{1}$
}

\begin{abstract}
Novel composite materials having desired performance properties can be developed by nanotechnology. The major objective of this research was to produce nanomaterial-reinforced particleboard composites with enhanced physical and mechanical performance. Urea formaldehyde adhesive used to produce particleboard composites was reinforced with nanoSiO${ }_{2}$, nano $\mathrm{Al}_{2} \mathrm{O}_{3}$, and nanoZnO at loading level of $0 \%, 1 \%$, and $3 \%$. To evaluate physical properties density, thickness swelling, water absorption, and equilibrium moisture content were determined while modulus of rupture, modulus of elasticity, bonding strength, and screw withdrawal strength tests were carried out to evaluate mechanical properties of the particleboard composites. The results acquired in this work revealed that nanomaterial reinforcement technique significantly affected the physical and mechanical performance properties of the particleboard composites. The findings showed that the modulus of rupture, modulus of elasticity, bonding strength, and screw withdrawal resistance of the composites improved by all the nanomaterials used in this study, except $3 \%$ nanoZnO. It was also determined that using $1 \%$ nanoSiO ${ }_{2}$ or $1 \%$ nano $\mathrm{Al}_{2} \mathrm{O}_{3}$ in the composites had the best results in the bonding strength and screw withdrawal resistance. The findings indicate that it is possible to produce novel wood composites by using proper nanomaterial type and loading level.
\end{abstract}

Keywords: Nanoparticles, nanoreinforced adhesives, nanoscience, nanotechnology, particleboard, wood composites.

\section{INTRODUCTION}

Nanotechnology has been identified as a technological revolution by scientists from all over the world (Ciraci 2005). It is expected to be a critical driver of global economic growth and development in this century because it is a multi-disciplinary field of research (USDA 2005). Because of its potential for business development, nanotechnology is of global interest (Shand 2010). The National Science Foundation of the United States predicts that within a decade, nanotechnology will be a one trillion dollar market and provide two million new jobs (USDA 2005). Nanoscience and nanotechnology also have numerous advantages for renewable biomaterials such as wood and wood composites (Candan 2012, USDA 2005, Roughley 2005).

\footnotetext{
Department of Forest Products Engineering, Faculty of Forestry, Istanbul University, Sariyer 34473, Istanbul, Turkey.

^Corresponding author: zekic@istanbul.edu.tr

Received: 02.01.2014 Accepted: 12.07.2014
} 
Nanoparticles can be used as fillers or additives in various polymers so that different enhancements in material properties can be achieved. They can also be used to reinforce thermosetting polymers to improve final performance properties. Therefore nanoparticles are receiving increased interest for research and development activities. Nanoparticles can extend application area of polymers. Polymer nanocomposites are multidisciplinary and promptly developing research area (Candan 2012, Gacitua et al. 2005, Uddin 2008). Formaldehyde-based adhesives including urea-formaldehyde, melamine-urea formaldehyde, and phenol-formaldehyde are the three most commonly used adhesives in wood-based panels industry (Moubarik et al. 2010). The influence of nanoparticle modified thermosetting adhesives on the mechanical performance properties of wood composite panels has been evaluated by several authors. Nanoparticle-reinforced composite sandwich panels and laminate flooring were developed by Candan (2012). Dimensional stability characteristics of nanoparticle-reinforced composite sandwich panels were investigated by Candan and Akbulut (2012a). Formaldehyde emission properties of the nanoparticle-reinforced laminate flooring were studied by Candan and Akbulut (2012b). It was stated that the nanomaterials significantly affected the formaldehyde emission of the laminate flooring. It was indicated that the lowest formaldehyde emission value was determined in the laminate flooring reinforced with nano $\mathrm{Al}_{2} \mathrm{O}_{3}(1 \%)$. Candan (2014) investigated the effect of nanocellulose on the formaldehyde emission of wood-based composite panels. It was revealed that environmentally friendly wood composites could be produced using nanocellulose.

The formaldehyde emission properties of particleboard and plywood panels reinforced with various nanoparticles at different loading levels were examined by Candan and Akbulut (2013). The authors reported that the nanoparticle type and loading level significantly affected the formaldehyde emission values of the particleboard and plywood panels. It was stated that the formaldehyde emission values of the plywood panels using $1 \%$ nanoZnO, $1 \%$ nanoAl2O3, and 3\% nanoSiO2 decreased by around $50 \%, 30 \%$, and $20 \%$, respectively. It was also concluded that the maximum decrease in formaldehyde emissions values of the particleboard panels was $82 \%$. Physical and mechanical performance properties of nanoparticle-reinforced plywood panels were examined by Candan and Akbulut (2014). It was stated that the nanomaterial-reinforcement technique significantly affected the physical and mechanical performance of the plywood panels. It was reported that modulus of rupture of the plywood panels have been improved by around $20 \%$ using $3 \%$ nano $_{2} \mathrm{O}_{2}$. The authors also concluded that the nano-engineered plywood panels had higher bonding strength values than those of the unreinforced plywood panels. Wood material was modified with montmorillonite nanoclay-reinforced melamine urea formaldehyde to obtain nanocomposites by Cai et al. (2008). Kordkheili et al. (2013) examined physical and mechanical properties of polymer type panels made from single wall carbon nanotubes and wood flour. Candan et al. (2013a) and Candan et al. (2014b) developed nanobiocomposites from carbon nanotubes (CNTs) and liquefied wood. Dynamic mechanical thermal analysis (DMTA), thermogravimetric analysis (TGA), and scanning electron microscope (SEM) analysis were carried out to characterize the novel nanocomposites.

Nanoclay-reinforced phenol formaldehyde (PF) was used as adhesive in manufacture of oriented strand lumber by Zhang and Smith (2010). The impact of nanoclay on the properties of the PF and phenol urea formaldehyde (PUR) was determined by Lei et al. (2010). It was stated that the addition of small percentages of nanoclay did not increase much the performance of PF and PUR resins used as adhesives for plywood and particleboard panels. Lei et al. (2008) reinforced urea formaldehyde (UF) with nanoclay and manufactured wood composite panels such as particleboard and plywood. Urea formaldehyde was reinforced with nanocellulose and used to produce plywood panels by Zhang et al. (2011). Urea formaldehyde and melamine urea formaldehyde were modified with nanocellulose and used in manufacture of particleboard and oriented strandboard by Veigel et al. (2012). Candan et al. (2013b) studied on nanocellulose-reinforced adhesives for wood composite panels. Candan et al. (2014a) developed nanocellulose-modified urea formaldehyde adhesives. The authors determined DMTA performance of the nanocellulose-modified adhesives. 
Particleboard composites are a type of wood-based composites which are made from wood particles as a renewable biomaterial. Particleboard composites are commonly used to produce furniture in Europe. The production capacity of particleboard is increasing year by year. Turkey is one of the biggest woodbased composite producers in Europe. Particleboard production capacity was 5,771,100 cubic meters in 2012 with 28 production lines (Candan 2012, Turkish Wood Based Panels Association 2013, Yildirim et al. 2013, Yildirim et al. 2014). Improving final performance properties of particleboard composites is of a great importance. For this aim, using nanotechnology application in wood composite manufacturing has a novelty. It can also be affect wood-based industry positively.

There is only limited work in the literature developing particleboard composites reinforced with nanoparticles such as nanoSiO${ }_{2}$, nano $\mathrm{Al}_{2} \mathrm{O}_{3}$, and nanoZnO. The objective of this present study was to develop particleboard composites having enhanced physical and mechanical properties by using nanoparticles. The effects of the nanoparticle type or nanoparticle loading level on the physical and mechanical properties of the particleboard composites were determined in this research.

\section{EXPERIMENTAL}

\section{Materials}

Wood particles, urea formaldehyde adhesive, hardener, and paraffin were supplied by Kastamonu Integrated Wood Industry and Trade Inc., located in Kastamonu, Turkey. The nanoSiO ${ }_{2}$, nano $\mathrm{Al}_{2} \mathrm{O}_{3}$, and nanoZnO particles used to reinforce urea formaldehyde adhesive were provided by a chemical company. The purity of the nanoparticles used in this study was $99,9 \%$. The average particle size (APS) values of the nanoSiO${ }_{2}$, nano $_{2} \mathrm{O}_{3}$, and nanoZnO were $15 \mathrm{~nm}, 15 \mathrm{~nm}$, and $20 \mathrm{~nm}$, respectively.

\section{Nanoreinforced composite manufacturing}

Urea formaldehyde adhesive was modified with nanoSiO $\mathrm{S}_{2}, \operatorname{nanoAl}_{2} \mathrm{O}_{3}$, and nanoZnO particles. The nanoparticles were added to adhesive at loading levels of $1 \%$ and $3 \%$. The nanoSiO2, nano $\mathrm{Al}_{2} \mathrm{O}_{3}$, and nanoZnO were mixed in the urea formaldehyde adhesive using a mechanical stirrer. Urea formaldehyde, $\mathrm{NH}_{4} \mathrm{C}_{1}$, and paraffin were used as adhesive, hardener, and hydrophobic additive, respectively, in the manufacture of the composites. Unreinforced composites as a control group without nanoparticles were also produced for comparison. Each composite group was produced with the three types of nanoparticles at the two tested loading levels. All composite groups were made in triplicate, giving a total of 21 composites for evaluation. The final thickness of the composites was $8 \mathrm{~mm}$.

\section{Testing procedure}

Nanoreinforced or unreinforced composites were cut into test samples which were then conditioned in a climate controlled chamber with a relative humidity of $65 \%$ and a temperature of $20^{\circ} \mathrm{C}$ until they reached an equilibrium moisture content, prior to the physical and mechanical tests. In this study, the dimensions of the all composite samples were determined according to TS EN 325 (2012).

\section{Physical and structural properties}

Density (TS EN 323, 1999), thickness swelling (TS) (TS EN 317, 1999), and water absorption (WA) (ASTM D1037, 2006) of the composites were determined according to national or international standards. Firstly, all TS and WA samples were weighed and measured in thickness. Specimens were immersed vertically in water bath with a temperature of $20^{\circ} \pm 1^{\circ} \mathrm{C}$. TS and WA performance of the composites were determined after 2 hours or 24 hours water immersion period. Equilibrium moisture content (EMC) test was also conducted according to ASTM D1037 (2006). The TS/WA samples were dried after the 24 hour water soaking period in an oven at $103^{\circ} \mathrm{C}$ until constant weights were reached and then weighed. The EMC values of the specimens after $2 \mathrm{~h}$ or $24 \mathrm{~h}$ water soaking period were calculated based on the oven-dry weight of each specimen. 
Scanning electron microscopy (SEM) analysis was carried out to determine structural characteristics of the nanoreinforced composites. SEM images were taken with a Field Emission-SEM (FEI Quanta FEG 450 , The Netherlands) operated at $20 \mathrm{kV}$. All the specimens were coated with gold prior to the analysis.

\section{Mechanical properties}

Modulus of rupture (MOR) (TS EN 310, 2011), modulus of elasticity (MOE) (TS EN 310, 2011), bonding strength (TS EN 319, 1999), and screw withdrawal resistance (TS EN 320, 2011) tests were performed to evaluate mechanical properties of the nanoreinforced or unreinforced composites.

\section{Statistical analysis}

All comparisons were first performed using an analysis of variance (two-way ANOVA) at $p<0,05$ to determine the effects of the nanoreinforcement technique on the physical and mechanical properties of the particleboard composites. Significant differences between the mean values of nanoreinforced and unreinforced composite groups were determined using Duncan's multiple range test.

\section{RESULTS AND DISCUSSION}

\section{Physical and morphological properties of the nanoreinforced composites}

The average density values of the nanoreinforced or unreinforced composites ranged between $0,65 \mathrm{~g} / \mathrm{cm}^{3}$ and $0,69 \mathrm{~g} / \mathrm{cm}^{3}$. The composite groups had similar density values. There was no important difference between the composite groups. Duncan's groupings also show that there was no significant difference in density values of the composites reinforced with nanoSiO${ }_{2}, \operatorname{nanoAl}_{2} \mathrm{O}_{3}$, and nanoZnO at a significance level of 0,05 . It can be also concluded that the composite manufacturing procedure has meticulously performed which is of a great importance to be obtained the composites having homogeneous performance properties in a group.

Average thickness swelling (TS) values of the nanoreinforced and unreinforced composites after $2 \mathrm{~h}, 24 \mathrm{~h}, 48 \mathrm{~h}$, and $96 \mathrm{~h}$ water soaking period were given in Table 1 . The findings clearly indicate that the TS values of the composites increased with increasing water soaking period from $2 \mathrm{~h}$ to $96 \mathrm{~h}$. The results show that the TS values of the nanoreinforced composites were significantly higher than those of unreinforced composites for $2 \mathrm{~h}, 24 \mathrm{~h}, 48 \mathrm{~h}$, and $96 \mathrm{~h}$ water soaking period. TS values after all water immersion periods of the nanoreinforced composites increased with increasing nanomaterial loading level. In case of nanoparticle type, the nanoSiO ${ }_{2}$ reinforced composites had the lowest TS values, followed by nano $\mathrm{Al}_{2} \mathrm{O}_{3}$ and nanoZnO reinforced composites. To investigate the effect of the nanomaterial loading level and nanomaterial type, a two-way ANOVA was carried out in this study. The results indicate that the TS values of the composites after all water soaking periods were significantly affected by the nanomaterial loading level, nanomaterial type, and combined effect of these factors. Duncan's groupings revealed that there was significant difference in all TS values of the composites reinforced with $0 \%, 1 \%$, and $3 \%$ nanomaterials. There were not significant differences between the composites reinforced with nanoSiO and nano $\mathrm{Al}_{2} \mathrm{O}_{3}$ at a significance level of 0,05 . 
Table 1. Average thickness swelling values of the nanoreinforced or unreinforced composites.

\begin{tabular}{|c|c|c|c|c|}
\hline \multirow{2}{*}{ Composites } & \multicolumn{4}{|c|}{ Thickness Swelling (\%) } \\
\hline & $2 \mathrm{~h}$ & $24 \mathrm{~h}$ & $48 \mathrm{~h}$ & $96 \mathrm{~h}$ \\
\hline Unreinforced & $17,67(1,15)$ & $21,73(1,45)$ & $22,72(1,60)$ & $23,82(1,71)$ \\
\hline $\mathrm{NanoSiO}_{2}(1 \%)$ & $20,85(2,03)$ & $25,23(2,42)$ & $26,27(2,35)$ & $27,92(2,58)$ \\
\hline $\mathrm{NanoSiO}_{2}(3 \%)$ & $22,99(3,43)$ & $28,01(4,40)$ & $29,30(4,66)$ & $30,52(4,53)$ \\
\hline $\mathrm{NanoAl}_{2} \mathrm{O}_{3}(1 \%)$ & $23,06(2,42)$ & $27,92(2,84)$ & $29,26(2,81)$ & $30,75(3,04)$ \\
\hline $\mathrm{NanoAl}_{2} \mathrm{O}_{3}(3 \%)$ & $24,05(2,68)$ & $28,30(3,05)$ & $29,23(2,92)$ & $31,03(3,26)$ \\
\hline NanoZnO (1\%) & $24,58(3,26)$ & $29,19(3,75)$ & $31,15(3,25)$ & $34,31(2,68)$ \\
\hline NanoZnO (3\%) & $33,47(6,44)$ & $40,42(7,23)$ & $41,02(6,94)$ & $44,76(6,23)$ \\
\hline
\end{tabular}

Effect of $\mathrm{Al}_{2} \mathrm{O}_{3}$ nanoparticles on thickness swelling properties of medium density fiberboard was examined by Kumar et al. (2013). It was reported that when the loading level of $\mathrm{Al}_{2} \mathrm{O}_{3}$ nanoparticles increased from $0 \%$ to $0,5 \%$, thickness swelling values of the panels decreased but further increase in nanoparticle loading level to $1 \%$ increased thickness swelling values of the panels. In this present study, the nanoparticles were used in the composites at a loading level of $1 \%$ or $3 \%$. It was obvious that lower loading level of nanoparticles had positive effect on thickness swelling while higher loading levels had adverse effect on the thickness swelling properties.

Water absorption (WA) results of the nanoreinforced or unreinforced composites after $2 \mathrm{~h}, 24 \mathrm{~h}$, $48 \mathrm{~h}$, and $96 \mathrm{~h}$ water soaking period was shown in Table 2 . The results reveal that WA values of the nanoreinforced composites were significantly higher than those of unreinforced composites for all water soaking periods. WA values after $2 \mathrm{~h}, 24 \mathrm{~h}, 48 \mathrm{~h}$, and $96 \mathrm{~h}$ water soaking period of the nanoZnOreinforced composites increased with increasing nanomaterial loading level. In case of nanomaterial type, the composites reinforced with nanoSiO 2 had the lowest WA values, followed by the composites reinforced with nano $\mathrm{Al}_{2} \mathrm{O}_{3}$, and the composites reinforced with nanoZnO. The highest WA values for all water soaking periods was determined in the composites reinforced with $3 \%$ NanoZnO. Two-way ANOVA was performed to evaluate the influence of the nanomaterial loading level, nanomaterial type, and combined effect of the factors on WA properties of the composites. The results indicate that the nanomaterial loading level, nanomaterial type, and combined effect of the two factors significantly affected the WA values of the composites after $2 \mathrm{~h}, 24 \mathrm{~h}, 48 \mathrm{~h}$, and $96 \mathrm{~h}$ water soaking period. Duncan's groupings showed that there was no significant difference in $2 \mathrm{~h}, 24 \mathrm{~h}, 48 \mathrm{~h}$, and $96 \mathrm{~h}$ WA values of the composites reinforced with $1 \%$ and $3 \%$ nanomaterials at a significance level of 0,05 .

Table 2. Average water absorption values of the nanoreinforced or unreinforced composites.

\begin{tabular}{|c|c|c|c|c|}
\hline \multirow{2}{*}{ Composites } & \multicolumn{4}{|c|}{ Water Absorption (\%) } \\
\hline & $2 \mathrm{~h}$ & $24 \mathrm{~h}$ & $48 \mathrm{~h}$ & $96 \mathrm{~h}$ \\
\hline Unreinforced & $71,72(6,70)$ & $88,23(7,45)$ & $91,31(8,47)$ & $101,70(10,39)$ \\
\hline $\mathrm{NanoSiO}_{2}(1 \%)$ & $77,81(4,44)$ & $91,81(4,94)$ & $92,86(3,43)$ & $103,58(6,12)$ \\
\hline $\mathrm{NanoSiO}_{2}(3 \%)$ & $75,07(3,58)$ & $88,62(3,14)$ & $89,30(2,64)$ & $99,52(7,15)$ \\
\hline $\mathrm{NanoAl}_{2} \mathrm{O}_{3}(1 \%)$ & $82,07(7,08)$ & $96,21(7,01)$ & $98,38(4,48)$ & $108,12(7,63)$ \\
\hline $\mathrm{NanoAl}_{2} \mathrm{O}_{3}(3 \%)$ & $80,58(5,66)$ & $96,03(5,53)$ & $98,60(5,25)$ & $109,06(6,89)$ \\
\hline NanoZnO (1\%) & $79,60(6,46)$ & $99,05(7,81)$ & $103,00(6,10)$ & $113,14(9,87)$ \\
\hline NanoZnO (3\%) & $86,89(9,56)$ & $107,89(11,29)$ & $112,02(9,90)$ & $126,10(10,62)$ \\
\hline
\end{tabular}

Standard deviation values are in parentheses 
Table 3 shows equilibrium moisture content (EMC) properties of the nanoreinforced or unreinforced composites after $2 \mathrm{~h}, 24 \mathrm{~h}, 48 \mathrm{~h}$, and $96 \mathrm{~h}$ water soaking period. The findings indicated that the nanoreinforced composites had significantly higher EMC values than those of unreinforced composites. EMC values after all water soaking periods of the nanoZnO-reinforced composites increased with increasing nanomaterial loading level. As for nanomaterial type, the nanoSiO${ }_{2}$ reinforced composites had the lowest EMC values, followed by nano $\mathrm{Al}_{2} \mathrm{O}_{3}$ reinforced composites and nanoZnO reinforced composites. A two-way ANOVA was carried out to determine the influence of the nanomaterial loading level, nanomaterial type, and combined effect of the two factors on the EMC values of the composites. The findings obviously show that EMC values of the composites after all water soaking periods were significantly affected by the nanomaterial loading level, nanomaterial type, and combined effect of these factors. Duncan's groupings revealed that difference in $2 \mathrm{~h}, 24 \mathrm{~h}, 48 \mathrm{~h}$, and $96 \mathrm{~h}$ EMC values of the composites reinforced with $1 \%$ and $3 \%$ nanomaterials was no significant at a significance level of 0,05 . There was significant difference in $24 \mathrm{~h}, 48 \mathrm{~h}$, and $96 \mathrm{~h} \mathrm{EMC} \mathrm{values} \mathrm{of} \mathrm{the} \mathrm{composites} \mathrm{reinforced} \mathrm{with} \mathrm{nanoSiO}{ }_{2}$, nano $\mathrm{Al}_{2} \mathrm{O}_{3}$, and nanoZnO at a significance level of 0,05 .

Table 3. Average equilibrium moisture content values of the nanoreinforced or unreinforced composites.

\begin{tabular}{lcccc}
\hline \multirow{2}{*}{ Composites } & \multicolumn{5}{c}{ Equilibrium Moisture Content (\%) } \\
\cline { 2 - 5 } & $2 \mathrm{~h}$ & $24 \mathrm{~h}$ & $48 \mathrm{~h}$ & $96 \mathrm{~h}$ \\
\hline Unreinforced & $91,54(8,13)$ & $110,29(9,48)$ & $112,09(9,71)$ & $123,62(11,90)$ \\
$\mathrm{NanoSiO}_{2}(1 \%)$ & $96,75(5,46)$ & $112,97(6,24)$ & $112,63(4,94)$ & $125,28(7,37)$ \\
$\mathrm{NanoSiO}_{2}(3 \%)$ & $94,44(4,27)$ & $109,48(3,82)$ & $110,26(3,18)$ & $123,83(6,41)$ \\
$\mathrm{NanoAl}_{2} \mathrm{O}_{3}(1 \%)$ & $102,36(8,22)$ & $118,08(8,17)$ & $120,46(3,04)$ & $130,60(8,66)$ \\
$\mathrm{NanoAl}_{2} \mathrm{O}_{3}(3 \%)$ & $101,40(6,92)$ & $118,63(6,82)$ & $120,49(6,42)$ & $133,18(8,95)$ \\
$\mathrm{NanoZnO}(1 \%)$ & $100,58(8,99)$ & $122,32(9,98)$ & $124,67(10,19)$ & $138,05(12,25)$ \\
$\mathrm{NanoZnO}(3 \%)$ & $111,43(12,22)$ & $135,19(14,29)$ & $138,56(12,66)$ & $153,40(14,06)$ \\
\hline \multicolumn{5}{c}{ Standard deviation values are in parentheses }
\end{tabular}

Figure 1 indicates scanning electron microscopy (SEM) micrographs of the nanoSiO${ }_{2}$, nano $_{2} \mathrm{Al}_{2}$, and nanoZnO particles used to produce the nanoreinforced composites. It clearly shows that all the nanoparticles are at nano-scale. Figure 2a, b, and c show SEM micrographs of the composites reinforced with nanoSiO${ }_{2}(1 \%)$, nano $\mathrm{Al}_{2} \mathrm{O}_{3}(1 \%)$, and nanoZnO (1\%), respectively. The SEM micrographs show that the nanomaterials were found to be embedded in the adhesive. It was also determined that the nanomaterials used to reinforce the composites were well dispersed in the matrix. On the other hand, it was observed that the nanomaterials tended to agglomeration when its loading level increased from $1 \%$ to $3 \%$. 


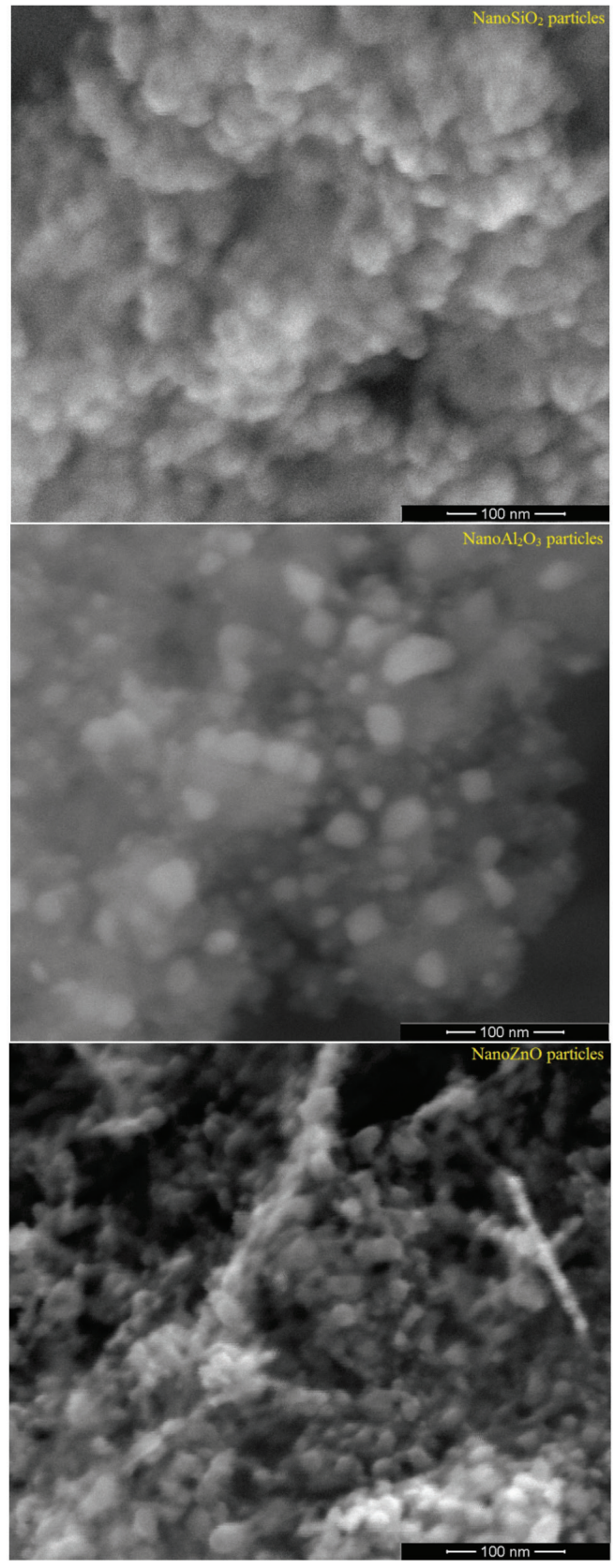

Figure 1. SEM micrographs of the nanoparticles. 

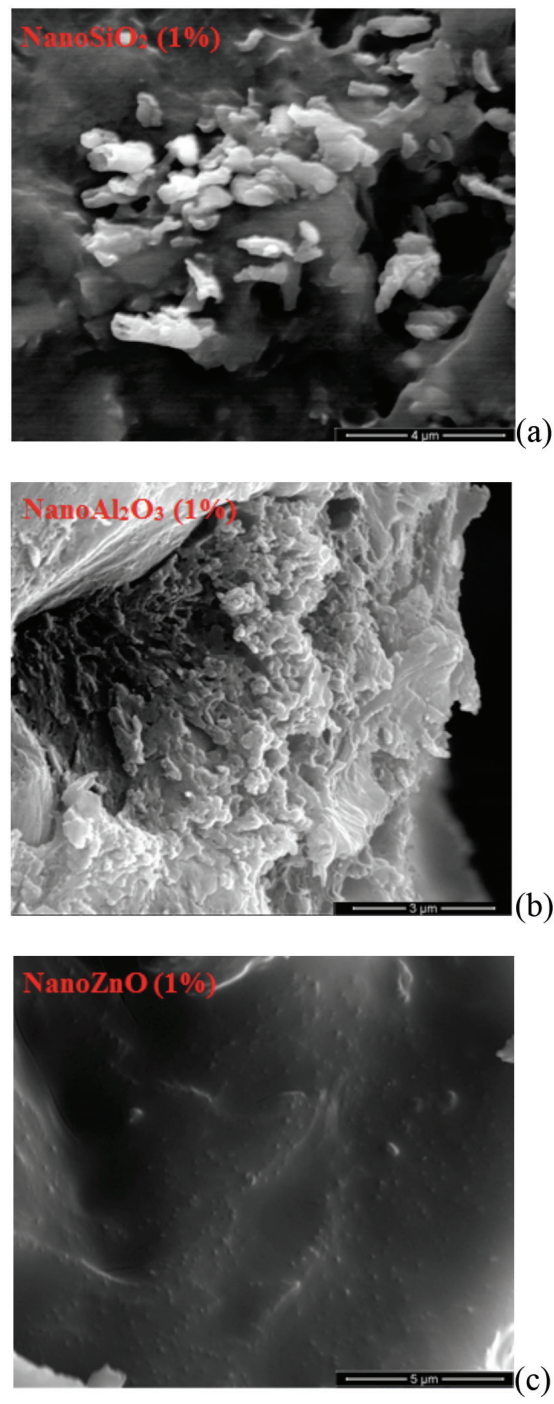

Figure 2. SEM micrographs of the nanoreinforced composites. 


\section{Mechanical properties of the nanoreinforced composites}

The modulus of rupture results of the nanoreinforced or unreinforced composites are given in figure 3. It clearly indicates that the nanomaterial reinforcement technique affected the modulus of rupture performance the composites.

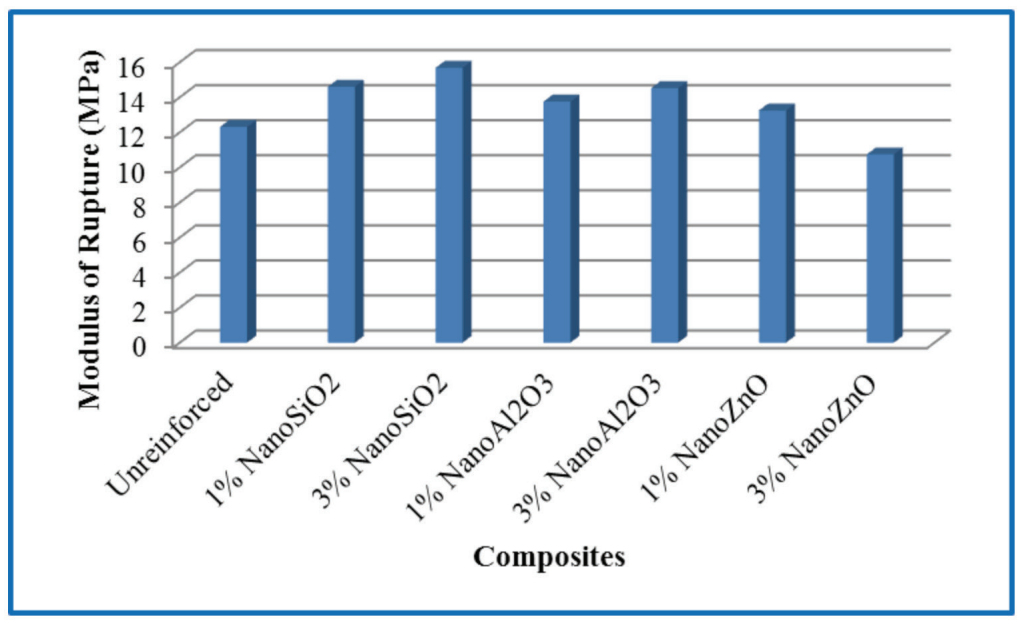

Figure 3. Modulus of rupture results of the nanoreinforced composites.

The modulus of rupture values of all the nanoreinforced composites were higher than those of the unreinforced composites, except than the composites reinforced with $3 \%$ nanoZnO. The modulus of rupture values of the composites reinforced with nanoSiO${ }_{2}$ or nano $\mathrm{Al}_{2} \mathrm{O}_{3}$ increased with increasing the nanomaterial loading level from $1 \%$ to $3 \%$. Whereas the values decreased with increasing the nanomaterial loading level in the composites reinforced with nanoZnO. The highest results in modulus of rupture were determined in 3\% nanoSiO 2 -reinforced composites with an improvement of around $27 \%$. Two-way ANOVA was carried out to evaluate the effect of the nanomaterial loading level, nanomaterial type, and the combined effect of the two factors on the modulus of rupture values of the composites. Table 4 indicates that the modulus of rupture values of the composites were significantly affected by the nanomaterial loading level, nanomaterial type, and combined effect of two factors. The synergetic effect was the most effective factor influencing the modulus of rupture of the composites with a partial eta squared value of 0,129 . It was followed by nanomaterial type and nanomaterial loading level with a partial eta squared values of 0,118 and 0,073 , respectively. Duncan's groupings indicated that difference in the modulus of rupture values of the nanoreinforced composites and unreinforced composites was significant while difference between $1 \%$ and $3 \%$ nanomaterial-reinforced composites was not significant at a significance level of 0,05 . It was also obtained that no significant difference was found in the modulus of rupture values of the composites reinforced with nanoSiO2 and nanoAl2O3 at a significance level of 0,05 .

Table 4. Two-way ANOVA results of the mechanical properties of the nanoreinforced or unreinforced composites.

\begin{tabular}{lcccc}
\hline Variable & MOR & MOE & $\begin{array}{c}\text { Bonding } \\
\text { Strength }\end{array}$ & $\begin{array}{c}\text { Screw Withdrawal } \\
\text { Resistance }\end{array}$ \\
\hline Nanomaterial loading level & $0,001^{*}$ & $0,000^{*}$ & $0,003^{*}$ & $0,000^{*}$ \\
Nanomaterial type & $0,000^{*}$ & $0,595(\mathrm{NS})$ & $0,000^{*}$ & $0,000^{*}$ \\
Nanomaterial loading level $\times$ & $0,000^{*}$ & $0,276(\mathrm{NS})$ & $0,004^{*}$ & $0,000^{*}$ \\
Nanomaterial type & & & \\
\hline * Indicates significance at 0,05 & & \\
NS: Non significant at 0,05 & \\
×: Interaction between nanomaterial loading level and nanomaterial type &
\end{tabular}




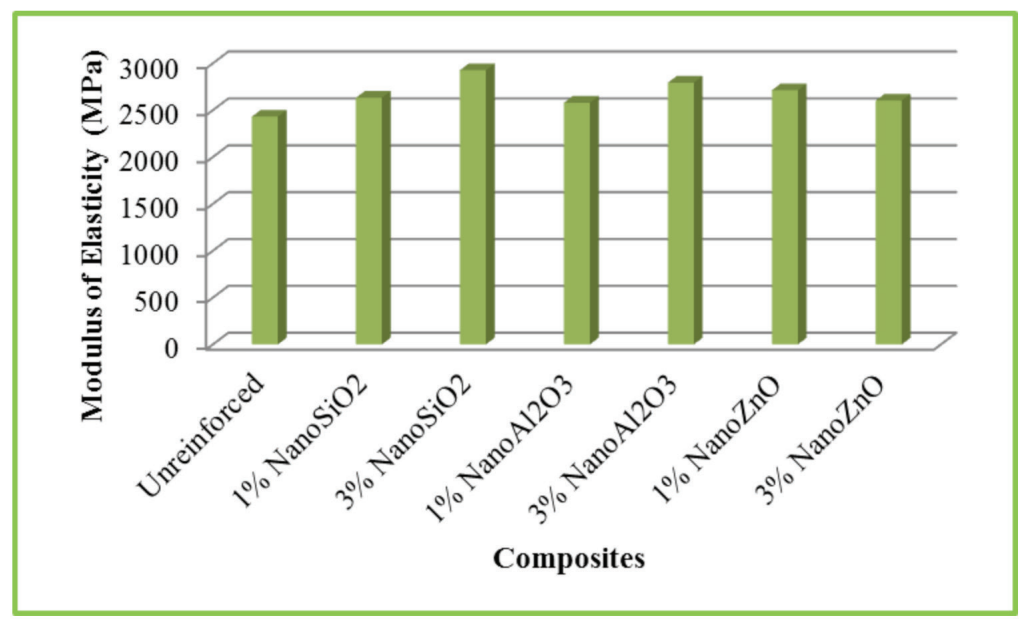

Figure 4. Modulus of elasticity results of the nanoreinforced composites.

Figure 4 shows the modulus of elasticity results of the nanoreinforced or unreinforced composites. It obviously indicates that all the nanoreinforced composite groups had higher modulus of elasticity values than those of the unreinforced composite group.

The modulus of elasticity values of the composites reinforced with nanoSiO $\mathrm{S}_{2}$ or nano $\mathrm{Al}_{2} \mathrm{O}_{3}$ increased as the nanomaterial loading level increased from $1 \%$ to $3 \%$ while the modulus of elasticity values decreased as nanomaterial loading level increased in the composites reinforced with nanoZnO. The highest modulus of elasticity value was obtained in $3 \%$ nanoSiO${ }_{2}$-reinforced composites with an improvement of around $20 \%$. To acquire the effect of the nanomaterial loading level, nanomaterial type, and the combined effect of the two factors on the modulus of elasticity performance of the composites, a two-way ANOVA was performed. As can be seen from table 4, the modulus of elasticity values of the composites were significantly affected by the nanomaterial loading level. It was obtained that both the nanomaterial type and the interaction between these factors had no significant effect on the modulus of elasticity values of the composites. Duncan's groupings showed that the nanoreinforcement technique significantly affected the modulus of elasticity values of the composites but difference in the modulus of elasticity values of the composites reinforced with $1 \%$ or $3 \%$ was not significant at a significance level of 0,05 . It was revealed that no significant difference was obtained in the modulus of elasticity values of the composites reinforced with nanoSiO, nanoAl $_{2} \mathrm{O}_{3}$, and nanoZnO at a significance level of 0,05 . The findings determined in this work were similar with findings which were found by Kumar et al. (2013). It was stated that $\mathrm{Al}_{2} \mathrm{O}_{3}$ nanoparticles were used to reinforce medium density fiberboard at a loading level of $0,5 \%$ and $1 \%$. It was reported that modulus of rupture and modulus of elasticity performance of the panels were affected by the reinforcement of $\mathrm{Al}_{2} \mathrm{O}_{3}$ nanoparticles. It was stated that modulus of elasticity values of the panels increased with increasing $\mathrm{Al}_{2} \mathrm{O}_{3}$ nanoparticles loading level from 0,5 to $1 \%$.

The average bonding strength values of the nanoreinforced and unreinforced composites are given in figure 5. It shows that all the nanoreinforced composites had higher bonding strength values than those of the unreinforced composites, except the composites reinforced with $3 \%$ nanoZnO. 


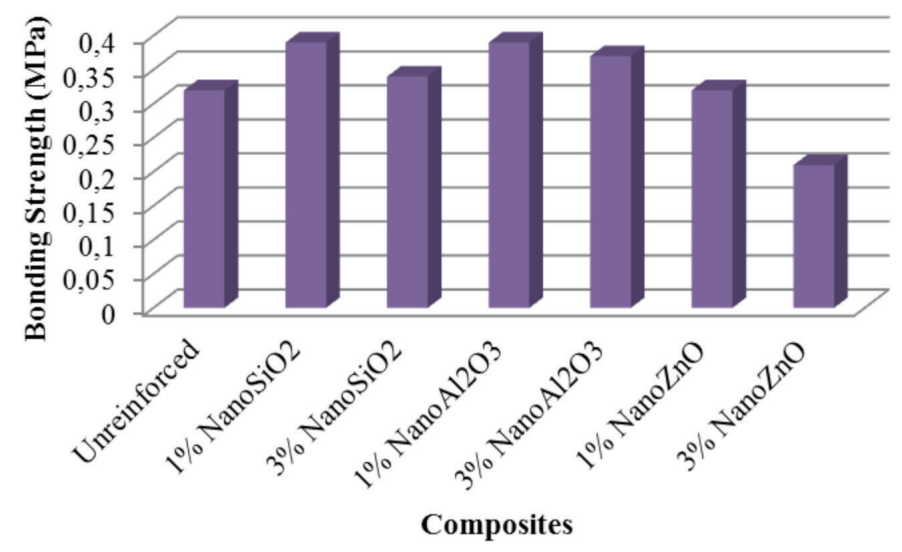

Figure 5. Bonding strength results of the nanoreinforced composites.

As can be clearly seen from figure 5 , the bonding strength values of the composites reinforced with nanoSiO ${ }_{2}$, nano $_{2} \mathrm{O}_{3}$, and nanoZnO decreased with increasing the nanomaterial loading level from $1 \%$ to $3 \%$. The composites reinforced with $1 \%$ nanoSiO ${ }_{2}$ or $1 \% \operatorname{nanoAl}_{2} \mathrm{O}_{3}$ had the highest bonding strength values with an increase of around $22 \%$. The results determined in this present study were supported by previous studies. Enhancement mechanism in bonding strength of nanoSiO 2 -reinforced plywood panels can be related to the enhanced wood-adhesive interaction and the elimination of voids on the wood surface by nanoSiO 2 (Xu et al. 2011). Kumar et al. (2013) used $\mathrm{Al}_{2} \mathrm{O}_{3}$ nanoparticles at a loading level of $0,5 \%$ and $1 \%$ to enhance performance properties of medium density fiberboard. It was stated that internal bonding strength of the panels reinforced with $\mathrm{Al}_{2} \mathrm{O}_{3}$ nanoparticles was higher than those of the panels without nanoparticles. The improvement in the mechanical properties of the nano $\mathrm{Al}_{2} \mathrm{O}_{3}$ reinforced composites can be due to improved heat transfer in the composites. Effect of nano $\mathrm{Al}_{2} \mathrm{O}_{3}$ on the heat transfer properties of medium density fiberboard was also investigated by Kumar et al. (2013). It was reported that enhanced heat transfer influenced urea-formaldehyde curing in the composites which resulted in increased performance in the composites. A two-way ANOVA was executed to determine the effect of the nanomaterial loading level, nanomaterial type, and the synergic effect of these factors on the bonding strength of the composites. Table 4 obviously shows that the nanomaterial loading level, nanomaterial type, and synergic effect of these factors significantly influenced the bonding strength values of the composites. The most effective factor affecting the bonding strength of the composites was the nanomaterial type with a partial eta squared value of 0,112 . It was followed by the synergic effect and nanomaterial loading level with a partial eta squared values of 0,082 and 0,062 , respectively. According to Duncan's groupings, the reinforcing the composites with the nanomaterials significantly affected the bonding performance. No significant difference was found in the bonding strength values of the composites reinforced with $0 \%$ and $3 \%$ at a significance level of 0,05 . It was also determined that difference between the bonding strength values of the nanoSiO${ }_{2}$ or nano $\mathrm{Al}_{2} \mathrm{O}_{3}$ reinforced composites was not significant at a significance level of 0,05 .

The screw withdrawal resistance results of the nanoreinforced or unreinforced composites are shown in Figure 6. The results acquired in this study obviously indicated that the screw withdrawal resistance of the composites reinforced with nanomaterials was higher than those of the unreinforced composites except the composites reinforced with $3 \%$ nanoZnO. The findings revealed that the highest screw withdrawal resistance values were determined in the composites reinforced with nanoSiO at a loading level of $1 \%$, whereas the lowest screw withdrawal resistance values were obtained in the composites reinforced with nanoZnO at a loading level of 3\%. Maximum increase in the screw withdrawal resistance was around $7 \%$. 


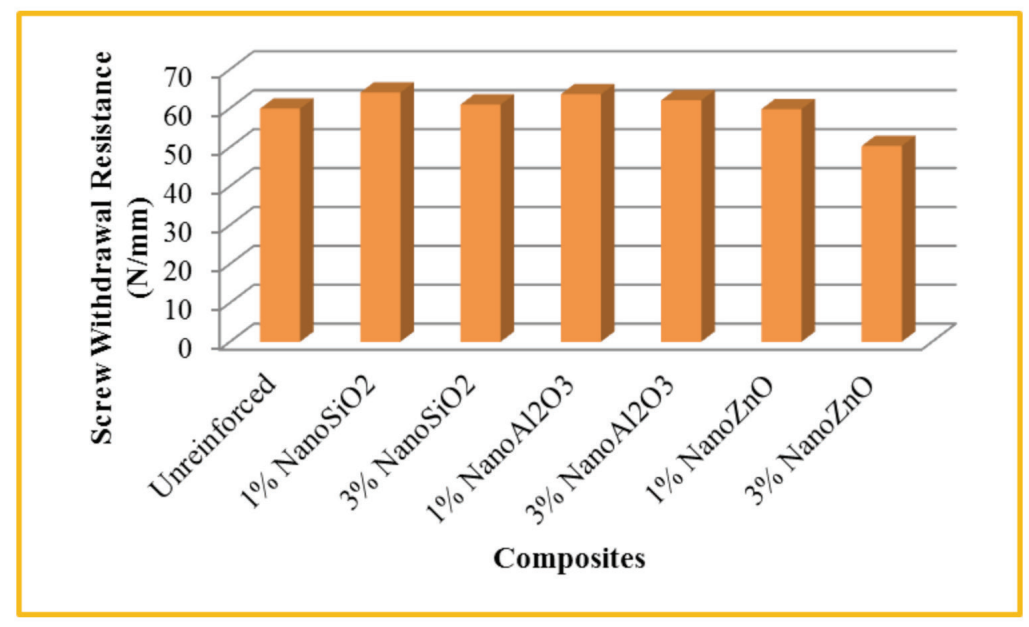

Figure 6. Screw withdrawal resistance results of the nanoreinforced composites.

Figure 6 also indicates that the screw withdrawal resistance values of the nanoreinforced composites decreased with increasing nanomaterial loading level. Statistical analysis was carried out to determine effect of the factors on the screw withdrawal resistance of the composites (Table 4). It shows that the nanomaterial loading level, nanomaterial type, and the synergic effect of these factors significantly affected the screw withdrawal resistance of the composites. The nanomaterial type was found to be the most effective factor influencing the screw withdrawal resistance of the composites with a partial eta squared value of 0,233 . It was followed by the synergic effect of the two factors and nanomaterial loading level with a partial eta squared value of 0,198 and 0,158 , respectively. Duncan's grouping findings showed that significant difference was found in the screw withdrawal resistance values of the composites reinforced with $0 \%, 1 \%$, and $3 \%$ nanomaterial at a significance level of 0,05 . It was also obtained that there was no significant difference in the screw withdrawal resistance values of the composites reinforced with nanoSiO 2 or nano $\mathrm{Al}_{2} \mathrm{O}_{3}$ at a significance level of 0,05 .

The results obtained in this present work are supported by a previous work by Salari et al. (2013). That work investigated the effect of $\mathrm{SiO}_{2}$ nanoparticles on the mechanical properties of oriented strandboard. In that study, urea-formaldehyde was reinforced with $\mathrm{SiO}_{2}$ nanoparticles at loading level of 1, 3 and 5 phc. It was reported that bonding strength and screw withdrawal resistance of the oriented strandboard reinforced with $\mathrm{SiO}_{2}$ nanoparticles were higher than those of the control panels. Jiang et al. (2013) examined the influence of $\mathrm{SiO}_{2}$ nanoparticles on the properties of nanoSiO$/$ /urea-formaldehyde-performed polymer composites. It was reported that the bonding strength of the wood modified by nano-UFP significantly improved. $\mathrm{Xu}$ et al. (2011) modified soy protein adhesive with $\mathrm{SiO}_{2}$ nanoparticles at a loading level of $0 ; 0,5 ; 1$; and $2 \%$ and then produced plywood panels. It was concluded that dry bonding strength of the panels significantly increased by addition of $\mathrm{SiO}_{2}$ nanoparticles up to $1 \%$. It was also reported that further increase in $\mathrm{SiO}_{2}$ nanoparticle loading level decreased the bonding strength of the panels. 


\section{CONCLUSIONS}

It is well known that bonding performance, modulus of rupture, modulus of elasticity, and screw withdrawal resistance are important performance characteristics for composites which are made from renewable biomaterials. Nanotechnology offers a number of opportunities to producing novel materials. Therefore developing new composites having enhanced performance properties was objected in this present work. $\mathrm{NanoSiO}_{2}$, nano $\mathrm{Al}_{2} \mathrm{O}_{3}$, and nanoZnO were used to reinforce particleboard composites at different loading levels in this study.

The findings obtained in this research clearly indicated that the nanoreinforcement technique significantly affected the physical and mechanical properties of the composites. It was determined that the modulus of rupture, modulus of elasticity, bonding strength, and screw withdrawal resistance of the composites improved by all the nanomaterials used in this study, except $3 \%$ nanoZnO. It was concluded that using $1 \%$ nanoSiO 2 or $1 \%$ nano $\mathrm{Al}_{2} \mathrm{O}_{3}$ in the composite matrix had the best results in the bonding strength and screw withdrawal resistance. As for modulus of rupture and modulus of elasticity, the highest performance was obtained in the composites reinforced with $3 \% \operatorname{nanoSiO}_{2}$. It was suggested that nanoZnO can be used to enhance performance properties of the composites with a lower loading level.

The results showed that the nanoparticles had a negative effect on the dimensional stability properties such as thickness swelling and water absorption of the composites. When lower nanoparticle loading levels are used, the negative effect of the nanoparticles on the dimensional stability can be minimized but it can be produced composites with improved mechanical performance. It was concluded that the physical and mechanical performance properties of the composites can be enhanced using proper nanomaterial loading level and nanomaterial type.

\section{ACKNOWLEDGEMENTS}

The authors thank Istanbul University Research Fund for its financial support in this study (Project No: 4806 and Project No: 19515). The authors would like to thank Gokhan Basarir and Enus Koc who are from Kastamonu Integrated Wood Industry and Trade Inc., Kastamonu, Turkey, for their valuable support in this study. 


\section{REFERENCES}

American Society for Testing and Materials. ASTM. 2006. Standard methods of evaluating the properties of wood - based fiber and particle panel materials. ASTM D1037 - 06, 2006, Philadelphia, PA, USA.

Cai, X.; Riedl, B.; Zhang, S.Y.; Wan, H. 2008. The impact of the nature of nanofillers on the performance of wood polymer nanocomposites. Compos Part A Appl Sci Manuf 39:727-737.

Candan, Z. 2012. Nanoparticles use in manufacture of wood-based sandwich panels and laminate flooring and its effects on technological properties. PhD Dissertation, 309 pp., Istanbul University, Istanbul, Turkey.

Candan, Z.; Akbulut, T. 2012a. Dimensional stability properties of nanoparticle reinforced composite sandwich panels. 8th Nanoscience and Nanotechnology Congress, June 25 - 29, 2012, Ankara, Turkey.

Candan, Z.; Akbulut, T. 2012b. Development of low formaldehyde-emitting laminate flooring by nanomaterial reinforcement. Proceedings of the $55^{\text {th }}$ International Convention of Society of Wood Science and Technology, August 27-31, 2012, Beiijng, China.

Candan, Z.; Akbulut, T. 2013. Developing environmentally friendly wood composite panels by nanotechnology. BioResources 8(3):3590-3598.

Candan, Z. 2014. Environmentally friendly wood composites by nanocellulose. COST FP1205, October 15 - 16, 2014, Madrid, Spain.

Candan, Z.; Akbulut, T. 2014. Nano-engineered plywood panels: Performance properties. Composites Part B: Engineering 64:155-161.

Candan, Z.; Gonultas, O.; Akbulut, T.; Balaban Ucar, M. 2013a. Development of carbon nanotube reinforced biocomposites for aerospace and automotive applications. 67 $7^{\text {th }}$ Forest Products Society International Convention, June 9 - 11, 2013, TX, USA.

Candan, Z.; Gonultas, O.; Akbulut, T. 2013b. Nanocellulose reinforced adhesives for wood composites. COST FP1205, December 3 - 4, 2013, Goteborg, Sweden.

Candan, Z.; Akbulut, T.; Gonultas, O. 2014a. Dynamic mechanical thermal analysis (DMTA) of nanocellulose reinforced urea-formaldehyde resin. COST FP1205, March 5-6, 2014, Bangor, United Kingdom.

Candan, Z.; Gonultas, O.; Akbulut, T.; Balaban Ucar, M. 2014b. Characterization of carbon nanotubes reinforced biocomposites. $3^{\text {rd }}$ International Non-Wood Forest Products Symposium, May $08-10,2014$, Kahramanmaras, Turkey.

Ciraci, S. 2005. Science and technology at one of a billionth of a meter. Science and Technique, Tubitak, Ankara, Turkey.

Gacitua, W.; Ballerini, A.; Zhang, J. 2005. Polymer nanocomposites: synthetic and natural fillers. A Review. Maderas. Ciencia y tecnologia 7(3):159-178.

Jiang, Y.; Wu, G.; Chen, H.; Song, S.; Pu, J. 2013. Preparation of nano-SiO 2 modified ureaformaldehyde performed polymer to enhance wood properties. Rev Adv Mater Sci 33(1):46-50. 
Kordkheili, H.Y.; Farsi, M.; Rezazadeh, Z. 2013. Physical, mechanical and morphological properties of polymer composites manufactured from carbon nanotubes and wood flour. Compos Part B 44:750-755.

Kumar, A.; Gupta, A.; Sharma, K.V.; Nasir, M. 2013. Use of aluminum oxide nanoparticles in wood composites to enhance the heat transfer during hot-pressing. Eur J Wood Prod 71:193-198.

Lei, H.; Du, G.; Pizzi, A.; Celzard, A. 2008. Influence of nanoclay on urea-formaldehyde resins for wood adhesives and its model. J Appl Polym Sci 109:2442-2451.

Lei, H.; Du, G.; Pizzi, A.; Celzard, A.; Fang, Q. 2010. Influence of nanoclay on phenol-formaldehyde and phenol-urea-formaldehyde resins for wood adhesives. J Adhes Sci Technol 24(8-10):1567-1576.

Moubarik, A.; Allal, A.; Pizzi, A.; Charrier, F.; Charrier, B. 2010. Preparation and mechanical characterization of particleboard made from maritime pine and glued with bio-adhesives based on cornstarch and tannins. Maderas. Ciencia y tecnologia 12(3):189-197.

Roughley, D.J. 2005. Nanotechnology: Implications for the wood products industry. Forintek Canada Corporation, 73 pp., Canada.

Salari, A.; Tabarsa, T.; Khazaeian, A.; Saraeian, A. 2013. Improving some of applied properties of oriented strand board (OSB) made from underutilized low quality paulownia (Paulownia fortunie) wood employing nano-SiO ${ }_{2}$. Ind Crops Prod 42:1-9.

Shand, F. 2010. What is nanotechnology? a guide. Nano, The Magazine for Small Science, 6 The Alpha Centre, Stirling University Innovation Park, Stirling, United Kingdom, 16 pp.

Turkish Standard Institute. TS. 2011. Wood-Based panels - Determination of modulus of elasticity in bending and of bending strength. TS EN 310. 2011. Ankara, Turkey.

Turkish Standard Institute. TS. 1999. Particleboards and fibreboards - Determination of swelling in thickness after immersion in water. TS EN 317. 1999. Ankara, Turkey.

Turkish Standard Institute. TS. 1999. Particleboards and fibreboards - Determination of tensile strength perpendicular to the plane of the board. TS EN 319. 1999. Ankara, Turkey.

Turkish Standard Institute. TS. 2011. Particleboards and fibreboards - Determination of resistance to axial withdrawal of screws. TS EN 320. 2011. Ankara, Turkey.

Turkish Standard Institute. TS. 1999. Wood-based panels - Determination of density. TS EN 323. 1999. Ankara, Turkey.

Turkish Standard Institute. TS. 2012. Wood-based panels - Determination of dimensions of test pieces. TS EN 325. 2012. Ankara, Turkey.

Turkish Wood Based Panels Association. 2013. Wood based panels production capacity reports. Istanbul, Turkey.

Uddin, F. 2008. Clays, nanoclays, and montmorillonite minerals. Metallurgical and Materials Transactions A (39):2804-2814. 
USDA. 2005. Nanotechnology for the forest products industry - Vision and technology roadmap. Based on the Results of the Nanotechnology for the Forest Products Industry Workshop, Landsdowne, Virginia, USA, October 17 - 19, 2004, TAPPI Press, Atlanta, GA, USDA, Forest Service, FPL. USA, 92.

Veigel, S.; Rathke, J.; Weigl, M.; Gindl-Altmutter, W. 2012. Particle board and oriented strand board prepared with nanocellulose-reinforced adhesive. J Nanomater doi:10.1155/2012/158503.

Xu, H.N.; Ma, S.; Lv, W.; Wang, Z. 2011. Soy protein adhesives improved by $\mathrm{SiO}_{2}$ nanoparticles for plywoods. Pigment Resin Technol 40(3):191-195.

Yildirim, H.T.; Dayaniklioglu, S.; Candan Z. 2013. Raw material procurement policies of Turkish wood based panel industry. Proceedings of $56^{\text {th }}$ Society of Wood Science and Technology International Convention, June $9-11,2013$, TX, USA.

Yildirim, H.T.; Candan, Z.; Korkut, S. 2014. Wood-based panels industry in Turkey: Future raw material challenges and suggestions. Maderas. Ciencia y tecnologia 16(2):175-186.

Zhang, C.; Smith, G.D. 2010. Effect of nanoclay addition to phenol-formaldehyde resin on the permeability of oriented strand lumber. Wood Fiber Sci 42(4):1-3.

Zhang, H.; Zhang, J.; Shong, S.; Wu, G.; Pu, J. 2011. Modified nanocrystalline cellulose from two kinds of modifiers used for improving formaldehyde emission and bonding strength of urea-formaldehyde resin adhesive. BioResources 6(4):4430-4438. 